\title{
The Place of Pedagogical Content Knowledge in Teacher Edu- cation
}

\author{
Ayhan Karaman
}

The Department of Secondary Science and Mathematics Education, Canakkale Onsekiz Mart University, Canakkale, Turkey

Received: August 20, 2011 / Accepted: April 24, 2012

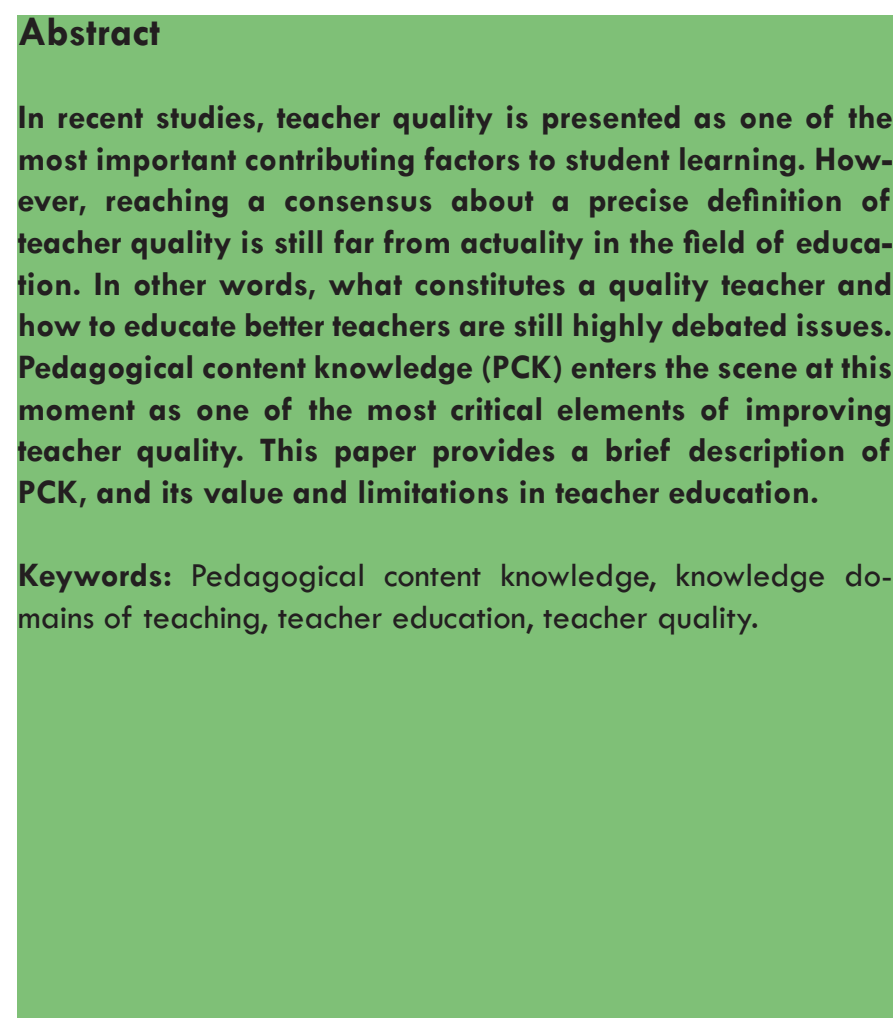

\section{Introduction}

The professional status of teachers has long been questioned by scholars in different academic disciplines (Eisner, 1995; Morey, Bezuk \& Chiero, 1997). Especially in the early 1980s, the dissatisfaction with the status of teaching and the academic quality of teachers gained momentum (Carlsen, 1999). In this time period, some of the teacher education reform movements such as the Holmes Group (1986) and Carnegie Forum on Education and the Economy (1986) supported the idea to professionalize teaching by increasing the level of academic knowledge that teachers gain in their university education (Hallinan \& Khmelkov, 2001). This period was also the revival of the debate on what knowledge teachers need to learn for effective teaching. Portraying the attributes and professional knowledge of teachers was considered to be a crucial aspect of strengthening the professional status of teaching. What key ideas teachers need to know in a subject area in order to discern them from the experts in that subject matter might be considered as the central idea to provide a portrait of the teacher professional knowledge.

In fact, the idea that there exists a special knowledge for teachers to learn in every field of subject matter has more than a century long history. Parr (1888) emphasized this subject-specific knowledge for teaching. 
An analysis of the process of teaching shows that there is a special knowledge in each subject that belongs to instruction. This is quite distinct from academic knowledge. It differs from it in purpose, in its relation to the facts of things, and in the mode by which it is obtained. (as cited in Bullough, 2001, p.658).

Likewise, Dewey (1902) also underlined the distinction between the subject matter for teachers and scientists by stating:

Every study or subject thus has two aspects: one for scientist as a scientist; the other for the teacher as a teacher. These two aspects are in no sense opposed or conflicting. But neither are they immediately identical. For the scientist, the subject matter represents simply a given body of truth to be employed in locating new problems, instituting new researches, and carrying them through to a verified outcome.... The problem of the teacher is a different one. As a teacher, he is not concerned with adding new facts to the science he teaches; in propounding new hypotheses or in verifying them. He is concerned with the subject matter of science as representing a given stage and phrases of the development of experience. (as cited in Deng, 2001, p.265).

Dewey seems to imply that teachers need to learn different aspects of subject matter than scientists do since each performs different roles in their own professions. This implied special knowledge for teachers encouraged scholars to define the domains of teacher knowledge in order to give a more professional identity to the teaching and to prepare academically and intellectually more capable teachers. Therefore, in 1980s, the domains of teacher professional knowledge for effective teaching became an important topic for scholarly discussion.

\section{Domains of Teacher Knowledge}

For a long time, what effective teachers need to know has been debated. Science teachers need more than content knowledge for successful teaching because being an expert in a field of science does not guarantee the delivery of a successful teaching. Shulman (1987) offered the concept of "the knowledge base of teaching" (p.5) in order to characterize the components of knowledge domains for effective teachers. In 1986a, Shulman proposed three categories of teacher knowledge: "Subject matter knowledge, pedagogical knowledge, and curricular knowledge" (p.26). Shulman (1986b) later scrutinized content knowledge and considered subject matter knowledge, pedagogical content knowledge, and curricular knowledge as the subcategories of content knowledge. Shulman (1986b) mentioned PCK for the first time in this paper by referring it as "subject matter knowledge for teaching" (p.9). He further expressed that PCK is "the particular form of content knowledge that embodies the aspects of content most germane to its teachability" (p.9). Shulman (1986b) underlined the need for more research on PCK by referring it as a "missing paradigm" (p.7). In his 1987 article, Shulman identified seven categories of knowledge bases for teaching: content knowledge, pedagogical knowledge, curricular knowledge, pedagogical content knowledge, knowledge of students, knowledge of educational context, and knowledge of educational outcomes. As might be noticed easily, Shulman's categorization of knowledge domains exhibits some differences from one paper to another (Carlsen, 1999). It seems that Shulman (1987) in this paper placed PCK not as a subcategory of content knowledge but as a unique domain of knowledge standing together with other knowledge domains. Shulman (1987) assigned a special place for PCK since it is the unique knowledge for teachers in order to deliver a successful teaching. He stated:

[PCK] identifies the distinctive bodies of knowledge for teaching. It represents the blending of content and pedagogy into an understanding of how particular topics, problems, or issues are organized, represented, and adapted to the diverse interests and abilities of learners, and presented for instruction. Pedagogical content knowledge is the category most likely to distinguish the understanding of the content specialist from that of the pedagogue. (p.8).

Scholars who later studied on teacher cognition offered different categories of teacher knowledge while Shulman's general categories of the knowledge base of teaching mainly remained stable (Carlsen, 1999). Grossman (1990) proposed four general areas of teacher knowledge as the cornerstones of the professional knowledge bases for teaching: "General pedagogical knowledge, subject matter knowledge, pedagogical content knowledge, and knowledge of context" (p.5). While acknowledging Shulman's seven categories of teacher knowledge, Morine-Dershimer and Kent (1999) contended that knowledge of educational outcomes are "inseparable from knowledge about evaluation and assessment procedures" (p.21). They included the component of "assessment procedures, evaluation of outcomes" (p.22) into Shulman (1987)'s teacher knowledge category of educational outcomes. They also considered Shulman (1987)'s knowledge category of educational context as consisting of two subcategories: "Knowledge of Specific Contexts" and "Knowledge of General Educational Context" (p.22). Likewise, Carlsen (1999) placed these two subcategories of educational context into Grossman (1990)'s four domains of teacher knowledge. Driel, Verloop, and Vos (1998) preferred to use the concept of "teachers' craft knowledge" (p.674) in order to refer to "the knowledge teachers have with respect to their teaching practice" (p.674). They elaborated the distinction between craft knowledge and knowledge base by stating, "Whereas Shulman's knowledge base encompasses every category of knowledge which may be relevant for teaching, our definition of craft knowledge is restricted to types of knowledge which actually guide the teachers' behavior during classroom practice" (p.675). They considered PCK as a specific form of teachers' craft knowledge. We might conclude that the categorizations of the domains of teacher knowledge display some variations from one scholar to another.

Several scholars agree that the borders between the domains of teachers' professional knowledge are fuzzy (e.g. Marks, 1990; Gess-Newsome, 1999; Magnusson, Krajcik \& Borko, 1999). It is really hard to sense where one domain of knowledge ends and the other one begins. Gess-Newsome (1999) expressed the difficulty of detecting teachers' knowledge base in practice by stating, "When observing an expert teacher, the movement from one knowledge base to the next will be seamless, giving the appearance of a single knowledge 
base for teaching" (p.1 1). "Assigning knowledge to specific categories is easier to accomplish in theory than in practice" (Essay Review, 2001, p.982). Shulman (1987) did not assume his categories of teacher knowledge to be final and stable but rather he acknowledged that as our understanding of teacher cognition develops, we have to reconsider and redefine our current categorization of teacher knowledge. However, Carlsen (1999) by embracing a poststructural view criticized those of the scholars who attempted to identify the components of teacher knowledge as adopting a structuralist view. He expressed that these structuralist models of teacher knowledge conceived knowledge as fixed and systematic, exhibited a naïve approach to power and knowledge relationship, and failed to represent the historical and cultural aspects of knowledge. Carlsen (1999) implied the limited usefulness of the structuralist models by stating that these models "are best viewed as a heuristic, not an immutable roadmap of any real individual's cognitive structure" (p.135). It would not be wrong to say that teachers' knowledge structures are very complex (Morine-Dershimer \& Kent, 1999) and hard to conceptualize.

\section{PCK Construct and lts Components}

Shulman (1987) defined seven distinct domains of teacher knowledge. He particularly placed a special emphasis on PCK construct due to its potential value for educating effective teachers. PCK is the "special amalgam of content and pedagogy that is uniquely the province of teachers, their own special form of professional understanding" (p.8). He defined PCK as being able "to transform the content knowledge...[a teacher] possesses into forms that are pedagogically powerful and yet adaptive to the variations in ability and background presented by the students" (p.15). He (1986b) articulated that PCK comprises:

The most regularly taught topics in one's subject area, the most useful forms of representations of those ideas, the most powerful analogies, illustrations, examples, explanations, and demonstrations-in a word, the ways of representing and formulating the subject that make it comprehensible to others....[It] also includes an understanding of what makes the learning of specific topics easy or difficult: the conceptions and preconceptions that students of different ages and backgrounds bring with them to the learning of those most frequently taught topics and lessons. (p.9).

It seems that Shulman's conceptualization of PCK includes two key elements: knowledge of the comprehensible representations of subject matter and understanding of students' conceptions and content-specific learning difficulties. Other scholars expanded Shulman's definition of PCK by adding new components to it but by generally keeping these two key elements in their definition (Driel, Verloop \& Vos, 1998).

As it was mentioned before, the borders between the knowledge domains are fuzzy (Marks, 1990). Hence, scholars argued if PCK exists as a separate construct from other knowledge domains including subject matter and general pedagogical knowledge. Gess-Newsome (1999) developed a teacher knowledge model in continuum with two extreme poles in order to conceptualize the nature of PCK. At one extreme (Integrative model),
PCK does not exist as a separate knowledge domain but can be conceived as the overlapping of three constructs: subject matter, pedagogy, and context. "Teaching, then, is the act of integrating knowledge across these three domains" (p.10). At the other extreme (Transformative model), PCK is conceptualized as the synthesis of all other knowledge domains including subject matter, pedagogy, and context, and constitutes a new shape of teacher knowledge, which is distinct from its original ingredients and "the only form of knowledge that impacts teaching practice" (p.10). Gess-Newsome (1999) used the mixture-compound metaphor in order to better represent integrative and transformative models. While the ingredients keep their original characteristics in a mixture and can be easily separable from the mixture, a compound is a new substance, which is totally distinct from its original ingredients. The metaphor of the chemical mixture and the compound is associated with integrative and transformative models respectively. The variety of definitions for PCK offered by different scholars might be located in somewhere between these two models, integrative or transformative (Gess-Newsome, 1999).

Several scholars from different academic backgrounds studied the construct of PCK and offered several components of PCK (e.g. Gudmundsdottir \& Shulman, 1987; Tamir, 1988; Grossman, 1990; Marks, 1990; Magnusson, Krajcik \& Borko, 1999). Grossman (1990) identified four major components of PCK: knowledge of instructional strategies, student conceptions, subject-specific curriculum, and purposes for teaching a subject. Tamir (1988) considered the knowledge of assessment as another component of PCK. By synthesizing the work of Grossman (1990) and Tamir (1988), Magnusson, Krajcik and Borko (1999) provided the following five components of PCK for science teaching:

(a) orientations toward science teaching, (b) knowledge and beliefs about science curriculum, (c) knowledge and beliefs about students' understanding of specific science topics, (d) knowledge and beliefs about assessment in science, and (e) knowledge and beliefs about instructional strategies for teaching science. (p.97).

Carlsen (1999) underlined the importance of understanding of student misconceptions in science education by including it as a component of PCK. Marks (1990) and Fernandez-Balboa and Stiehl (1995) regarded subject matter knowledge as one of the components of PCK. Fernandez-Balboa and Stiehl (1995) also proposed two types of PCK: generic PCK, "common to instruction across all subjects or content areas" (p.294) and specific PCK, "particular to the instruction of a specific subject or content area" (p.294). Cochran, DeRuiter and King (1993) renamed PCK as "pedagogical content knowing (PCKg)" (p.266) by emphasizing the dynamic nature of knowledge. They defined PCKg as "a teacher's integrated understanding of four components of pedagogy, subject matter content, student characteristics, and the environmental context of learning" (p.266).

Shulman conceptualized knowledge domains of teaching as distinct but interacting entities (Zeidler, 2002). Therefore, PCK with a structuralist perspective is a form of teacher knowledge which is separate from other forms but defined by its relationship to them (Carlsen, 1999). However, Carlsen (1999) by adopting 
a poststructuralist view, argued that PCK is not a fixed body of knowledge but rather its components are "formed anew in each new educational context" (p.139). He further underlined the significance of knowledge and power relationship in how PCK is conceptualized differently by different academic disciplines. $\mathrm{He}$ stated, "Even within a group having disciplinary homogeneity, asymmetries in power will affect the definition of knowledge" (p.139). He contended that PCK would take different forms if it was established by disciplinary specialists (e.g. physics educators) and scientific experts (e.g. engineers) respectively. Mason (1999) defined PCK as an ability, which can be developed by reflection and practice (Fernadez-Balboa \& Stiehl, 1995), "to combine knowledge of a specific discipline along with the teaching of that discipline" (p.279) rather than as a fixed body of knowledge.

How teachers' PCK development can be supported most effectively is still a challenging question. The integrative model implies that teachers can build up their knowledge structures independently and then integrate them to form their PCK (GessNewsome, 1999). This is what we see most of the time in science teacher education today. Prospective science teachers generally acquire their subject matter and pedagogical knowledge from different academic departments. Cochran, DeRuiter and King (1993) supported a more holistic approach to the science teacher education by criticizing the separate acquirement of subject matter and pedagogical knowledge. Shulman (1986b) believed that teachers should learn content knowledge different than subject matter experts. Cochran, DeRuiter and King (1993) suggested:

Teacher education programs should be deliberately designed to assist pre-service teachers to construct understanding of subject matter that differs from that of subject matter experts (i.e. biologist, historians, writers, or educational researchers), not in quality or quantity, but in how that understanding is used. (p.267).

They further argued that PCK develops with the simultaneous understanding of four components of teacher knowledge, pedagogy, subject matter, students, and environmental context. They stated, "The four components should not be acquired first and then somehow put together, but rather preparation programs should promote integration by having teachers simultaneously experience the PCKg [pedagogical content knowing] components" (p.268). Magnusson, Krajcik and Borko (1999) expressed that effective teachers need to develop their understanding of all aspects of PCK in all of the topics they teach.

\section{The Value and Limitations of PCK Construct}

There exist very few subjects like PCK which have been widely recognized and discussed by scholars in a relatively short period of time after its first appearance in less than two decades ago. The introduction of PCK by Shulman is a unique contribution to the research on teacher education since it directed people's attention to two most critical elements of teacher education, subject matter and pedagogical knowledge, which have long been divorced from each other (Morine-Dershimer \& Kent, 1999).
Gess-Newsome (1999) stressed some of the areas that the construct of PCK contributed as:

[PCK] revitalized the study of teacher knowledge, provided a new analytical frame for organizing and collecting data on teacher cognition, highlighted the importance of subject matter knowledge and its transformation for teaching, incorporated findings across related constructs, and provided for a more integrated vision of teacher knowledge and classroom practice. (p.10).

PCK concept is a unique domain of teacher knowledge which is critical to understand what effective science teachers need to know (Magnusson, Krajcik \& Borko, 1999). Teachers need PCK in order to organize the content of their lessons, to develop comprehensible representations of the topics they teach, to understand the possible difficulties that their students may encounter in a specific topic (Essay Review, 2001). PCK might also serve as a conceptual framework for establishing more effective science teacher education programs (Carlsen, 1999; Essay Review, 2001).

Despite helpful as a construct, PCK, of course, is not free from any criticism. PCK "is a complicated and inherently ambiguous notion that is open to myriad of interpretations" (Daehler \& Shinohara, 2001, p.268). McEwan and Bull (1991) questioned the need for PCK construct by arguing that all content knowledge has a pedagogical aspect since they must be communicated. Since the borders between knowledge domains are fuzzy, it is hard to conceptualize PCK as a separate construct. For that reason, Lederman and Gess-Newsome (1992) thought PCK as "more of a theoretical argument than a practical one" (p.19). Carlsen (1991) argued that there is not enough evidence to support the existence of PCK as a separate construct. However, Magnuson, Krajcik and Borko (1999) discussed that PCK as being a separate construct or not is a matter of how you choose to organize your knowledge domains. While PCK is theoretically a helpful construct to conceptualize the characteristics of an effective teacher, identifying the specific elements of PCK in practice is really hard (Gess-Newsome, 1999; Loughran, Milroy, Berry, Gunstone \& Mulhall, 2001). Because PCK is mostly an internal construct, it can not be observed easily (Baxter \& Lederman, 1999). Gess-Newsome (1999) expressed that there are indeed a few studies which claim to seize the specific elements of PCK. When it comes to measure teachers' PCK, the methodologies are usually time- consuming to design, implement and analyze (Baxter \& Lederman, 1999). Labaree (1992) more radically criticized PCK as nothing more than an invented construct to enhance the professional status of teacher educators.

\section{References}

Baxter JA and NG Lederman (1999) Assessment and measurement of pedagogical content knowledge. In J. Gess-Newsome \& N.G. Lederman (Eds.), Examining pedagogical content knowledge: The construct and its implications for science education. Dordrecht, the Netherlands: Kluwer Academic Publishers. pp. 147-161.

Bullough RV (2001) Pedagogical content knowledge circa 1907 and 1987: A study in the history of an idea. Teaching and Teacher Education 17: 655-666. 
Carlsen WS (1991) Subject matter knowledge and science teaching: A pragmatic perspective. In J. Brophy (Ed.), Advances in research on teaching. Greenwich, CT: JAI Press. Vol. 2, pp.115-144.

Carlsen WS (1999) Domains of teacher knowledge. In J. Gess-Newsome \& N.G. Lederman (Eds.), Examining pedagogical content knowledge: The construct and its implications for science education. Dordrecht, the Netherlands: Kluwer Academic Publishers. pp. 133144.

Carnegie Forum on Education and the Economy (1986) A nation prepared: Teachers for the $21^{\text {st }}$ century. New York: Author.

Cochran KF, JA DeRuiter, and RA King (1993) Pedagogical content knowing: An integrative model for teacher preparation. Journal of Teacher Education 44 (4): 263-273.

Daehler KR and M Shinohara (2001) A complete circuit is a complete circle: Exploring the potential of case materials and methods to develop teachers' content knowledge and pedagogical content knowledge of science. Research in Science Education 31: 267-288.

Deng Z (2001) The distinction between key ideas in teaching school physics and key ideas in the discipline of physics. Science Education 85: 263-278.

Driel JH van, N Verloop, and W de Vos (1998) Developing science teachers' pedagogical content knowledge. Journal of Research in Science Teaching 35 (6): 673-695.

Eisner EW (1995) Preparing teachers for schools of the 21 st century. Peabody Journal of Education 70 (3): 99-111.

Essay Review (2001) Pedagogical content knowledge: An integrative component within knowledge base for teaching. Teaching and Teacher Education 17: 979-986.

Fernandez-Balboa J and J Stiehl (1995) The generic nature of pedagogical content knowledge among college professors. Teaching and Teacher Education 11 (3): 293-306.

Gess-Newsome J (1999) Pedagogical content knowledge: An introduction and orientation. In J Gess-Newsome \& NG Lederman (Eds.), Examining pedagogical content knowledge: The construct and its implications for science education. Dordrecht, the Netherlands: Kluwer Academic Publishers. pp. 3-17.

Grossman PL (1990) The making of a teacher: Teacher knowledge and teacher Education. New York: Teachers College Press.

Gudmundsdottir S and LS Shulman (1987) Pedagogical content knowledge in social studies. Scandinavian Journal of Educational Research 31: 59-70.

Hallinan MT and VT Khmelkov (2001) Recent developments in teacher education in the United States of America. Journal of Education for Teaching 27 (2): 175-185.

Holmes Group (1986) Tomorrow's teachers: A report of the Holmes Group. East Lansing, Ml: Author.

Labaree DF (1992) Power, knowledge, and the rationalization of teaching: A genealogy of the movement to professionalize teaching. Harvard Educational Review 62: 123-154.

Lederman NG and J Gess-Newsome (1992) Do subject matter knowledge, pedagogical knowledge, and pedagogical content knowledge constitute the ideal gas law of science teaching? Journal of Science Teacher Education 3: 16-20.

Loughran J, P Milroy, A Berry, R Gunstone, and P Mulhall (2001) Documenting science teachers' pedagogical content knowledge through PaP-eRs. Research in Science Education 31: 289-307.

Magnusson S, J Krajcik, and H Borko (1999) Nature, sources, and development of pedagogical content knowledge for science teaching. In J. Gess-Newsome \& NG Lederman (Eds.), Examining pedagogical content knowledge: The construct and its implications for science education. Dordrecht, the Netherlands: Kluwer Academic Publishers pp.95-132.

Marks R (1990) Pedagogical content knowledge: From a mathematical case to a modified conception. Journal of Teacher Education 41: 3-11.

Mason CL (1999) The triad approach: A consensus for science teaching and learning. In J. Gess-Newsome \& N.G. Lederman (Eds.), Examining pedagogical content knowledge: The construct and its implications for science education. Dordrecht, the Netherlands: Kluwer Academic Publishers. pp.277-292.

McEwan H and B Bull (1991) The pedagogic nature of subject matter knowledge. American Educational Research Journal 28: 316-334.

Morey Al, N Bezuk, and R Chiero (1997) Preservice teacher preparation in the United States. Peabody Journal of Education 72 (1): 4-24.

Morine-Dershimer $G$ and T Kent (1999) The complex nature and sources of teachers' pedagogical knowledge. In J. Gess-Newsome \& N.G. Lederman (Eds.), Examining pedagogical content knowledge: The construct and its implications for science education. Dordrecht, the Netherlands: Kluwer Academic Publishers. pp. 21-50.

Shulman LS (1986a) Paradigms and research programs in the study of teaching: A contemporary perspective. In M.C. Wittrock (Ed.), Handbook of Research on Teaching (3rd ed., pp.3-36). New York: Macmillan.

Shulman LS (1986b) Those who understand: Knowledge growth in teaching. Educational Researcher 15 (2): 4-14.

Shulman LS (1987) Knowledge and teaching: Foundations of the new reform. Harvard Educational Review 57 (1): 1-22.

Tamir P (1988) Subject matter and related pedagogical knowledge in teacher education. Teaching and Teacher Education 4: 99-1 10.

Zeidler DL (2002) Dancing with maggots and saints: Visions for subject matter knowledge, pedagogical knowledge, and pedagogical content knowledge in science teacher education reform. Journal of Science Teacher Education 13 (1): 27-42. 